\title{
Investigation of carbon emissions due to COVID-19 vaccine inventory
}

\author{
Nita H. Shah ${ }^{1}$ (D) Ekta Patel ${ }^{1}$ (D) ${\text { Kavita } \text { Rabari }^{1} \text { (D) }}$
}

Received: 30 April 2021/Revised: 11 August 2021/Accepted: 16 August 2021/Published online: 6 September 2021

(C) The Society for Reliability Engineering, Quality and Operations Management (SREQOM), India and The Division of Operation and Maintenance, Lulea University of Technology, Sweden 2021

\begin{abstract}
Inventory model for vaccine of COVID-19 pandemic is the subject of analysis in the proposed article. The initial registration for vaccination and vaccination of registered individuals is taken during the period under consideration. The paper considers the utility of vaccine during storage, holding cost, purchase cost, manufacturing cost and inspection cost. A fraction of registered individuals who do not turn up for a vaccination is taken into account. All the actions by the player incur carbon emissions. During the whole procedure of vaccination starting from raw material to end user carbon emissions are observed. Carbon emissions in stocking raw material, during inspection, during purchase activity, during set-up and transportation phase and holding it at point of delivery. Maximum carbon emission of $28 \%$ occur during purchase activity followed by $21 \%$ during transportation at the point of delivery and stocking it at respective places. To follow green policy, carbon tax is levied. A non-linear formulation of the proposed problem is modelled to compute optimum cycle time without allowing shortages. The convexity of the objective function is established through the numerical data. Analysis of carbon emissions and carbon tax levied is carried out through the data. Research Objective: Carbon Emission is one of a cause for ozone layer depletion.
\end{abstract}

Nita H. Shah

nitahshah@gmail.com

Ekta Patel

ektapate11109@gmail.com

Kavita Rabari

kavitagalchar1994@gmail.com

1 Department of Mathematics, Gujarat University, Ahmedabad, Gujarat 380009, India
Moreover, it causes many ecological disturbances resulting into several environmental temperature variations. These all problem affect an individual's health. So, there arise a need to frame a mathematical model to decipher relationship between COVID-19 vaccine inventory and effect of carbon emissions.

Keywords Vaccine inventory - Quality inspection . Carbon emissions $\cdot$ Carbon tax $\cdot$ Spoilage of vaccine

\section{Introduction}

In late 2019, a novel infectious disease of the coronavirus family (COVID-19) was identified in Wuhan city of China, which has transformed quickly into a perplexity. The pandemic is a powerful warning of the capacity of infectious diseases to disturb the most advanced societies. Worldwide reports of the ongoing disaster show more than 113 million infected cases of the infection (worldometers).

Due to the effect of COVID-19 worldwide, several projects were shifted which focused on pandemic-related medications and it has primarily been a reason for financial growth for the pharmaceutical industry. Globally, both positive and negative effects are observed due to such pandemics. In the past, for developing vaccines, it went through several steps but due to the urgent need for COVID-19 vaccines, the process was happening parallelly while maintaining strict clinical as well as safety measures. Recent progression/invention of COVID-19 vaccine requires sustainable cooling technologies, transportation and preservation strategies, etc. which results in an increase in carbon emission. 
Carbon dioxide emission is attributed to both natural and human sources where natural sources include decomposition, respiration, etc. and human sources involve deforestation, burning of fossil fuels, etc. Additionally, it is rarely noticed that the pharmacy sector evokes images of pollution, smoke stack, environmental damages, etc. Proposed article is structured as follows: A succinct survey of prior literature is provided in Sect. 2. The assumptions and notations are demonstrated in Sect. 3. Section 4 represents the model description. Section 5 defines model development. Numerical solution is proposed in Sect. 5. Sensitivity analysis carried out in Sect. 6. Discussion of findings is presented in Sect. 7. Section 8 concludes the proposed model.

\section{Literature survey}

\subsection{Inventory for growing items}

In the literature of inventory, substantial attention has not been paid to the inventory model for growing items. In this context, Rezaei (2014) was the first to introduce the concept of growing items to inventory researchers by calculating the optimal order quantity at the start of the growing cycle. This model deliberates the situation in which newborn animals are purchased and after growth, these animals are slaughtered and sold out. For instance, Nobil et al. (2019) extended Rezaei (2014) model by taking linearly increasing growth function and shortages are fully backordered. After that Sebatjane and Adetunji (2019a, b, c) established an EOQ model for growing items with imperfect quality by assuming a quality screening process in which all the slaughtered items are checked before they are sold out. Khalilpourazari and Pasandideh (2019) proposed multi item economic order quantity for growing items with a limited management budget and available warehouse space. Malekitabar et al. (2019) investigated the inventory model for growing-mortal in a two-echelon supply chain with a supplier and a farmer. Furthermore, Sebatjane and Adetunji (2019a, b, c) formulated three echelon supply chain inventory model for growing items with farming, processing and retail operations. Hidayat et al. (2020) developed an EOQ model for growing items by considering unlimited capacity and an unlimited budget. Later on, this model was known as the Wilson model. Some research focused on the inventory model for growing items of quality aspects. Zhang et al. (2016) discussed the inventory model for growing items for carbon-constrained the total cost, carbon emission and the optimal slaughter time. Alfares and Afzal (2021) developed an inventory model for growing items with a growth period and consumption period in which quality inspection and shortages are considerable.

\subsection{Inventory for carbon emissions}

In order to improve global warming, the total amount of carbon emission can be curbed because it is one of the most effective market-based mechanisms. So, organizations can optimize their strategic decisions in production, transportation and in inventory management to reduce carbon emission. There are some studies of operations decisions based on the carbon emission. Hereof, Hua et al. (2011a, b) proposed an inventory policy for managing carbon footprints with carbon emission. Asbi et al. (2013) studied carbon emission limitations in the multi-sourcing lot-sizing problem. Toptal et al. (2014) analyzed the joint inventory model and carbon emission reduction under carbon cap, tax and cap-and-trade policies. Lou et al. (2015) established a supply chain model for carbon emission technology investment. Dye and Yang (2015) studied the stability of the inventory model for default risk and demand which depends on the length of credit period under the carbon cap-and-trade policy. Moreover, this model is finished with carbon offset policy. Datta (2017) scrutinized the effect of green technology on a production inventory model by assuming price-sensitive demand under carbon tax policy. Mishra et al. (2020) proposed a sustainable economic production quantity model under carbon cap and carbon tax. For controlling carbon emission, green technology investment is applied in both cases: with shortages and without shortages and shortages are partially and fully backlogging. Mishra et al. (2021) analyzed a sustainable inventory model under carbon cap and tax regulation policies in which demand is price sensitive. This study includes the investment in green technology and preservation technology under different backorder situations for controlling carbon emission Table 1.

\section{Problem statement, assumption and notations}

In this section, problem statement is given. Next follows notations and assumptions for the proposed model formulation.

\subsection{Problem statement}

The aim of the research exhibited here is to analyze inventory of Vaccine for prevailing pandemic COVID-19. 
Table 1 Literature survey

\begin{tabular}{|c|c|c|c|c|}
\hline Title & $\begin{array}{l}\text { Growing } \\
\text { item }\end{array}$ & $\begin{array}{l}\text { Carbon } \\
\text { emissions }\end{array}$ & Demand pattern & Carbon regulation policy \\
\hline Hua et al. (2011a, b) & & & & Carbon trade and cap \\
\hline \multicolumn{5}{|l|}{ Asbi et al. (2013) } \\
\hline Toptal et al. (2014) & & & & Carbon cap, tax and cap-and-trade \\
\hline \multicolumn{5}{|l|}{ Rezaei (2014) } \\
\hline Lou et al. (2015) & & & & Carbon trade \\
\hline Dye and Yang (2015) & & & $\begin{array}{l}\text { Length of the credit } \\
\text { period }\end{array}$ & $\begin{array}{l}\text { Carbon cap-and-trade and carbon } \\
\text { offset }\end{array}$ \\
\hline \multicolumn{5}{|l|}{ Zhang et al. (2016) } \\
\hline Datta (2017) & & & Price sensitive & Carbon tax \\
\hline \multicolumn{5}{|l|}{ Nobil et al. (2019) } \\
\hline \multicolumn{5}{|c|}{ Sebatjane and Adetunji (2019a, b, c) } \\
\hline \multicolumn{5}{|c|}{$\begin{array}{l}\text { Khalilpourazari and Pasandideh } \\
\text { (2019) }\end{array}$} \\
\hline \multicolumn{5}{|c|}{ Malekitabar et al. (2019) } \\
\hline \multicolumn{5}{|c|}{ Sebatjane and Adetunji (2019a, b, c) } \\
\hline \multicolumn{5}{|l|}{ Hidayat et al. (2020) } \\
\hline Mishra et al. (2020) & & & & Carbon cap and tax \\
\hline \multicolumn{5}{|c|}{ Alfares and Afzal (2021) } \\
\hline Mishra et al. (2021) & & & Price sensitive & Carbon cap and tax \\
\hline Proposed article & & & $\begin{array}{l}\text { Carbon emissions } \\
\text { sensitive }\end{array}$ & Carbon tax \\
\hline
\end{tabular}

The process starts with buying raw material for vaccine production, manufacturing vaccine, stocking it in a specialized warehouse, transporting it to distribution center. Each of these processes observes carbon emission. The government started vaccinated program in phases. The registration is required for vaccination. It is evident that demand depends on the registration. The non-arrival of individuals even after registration and loss of utility of vaccine is considered in the formulation of the model. The focus of the study is to compute carbon emissions during the process of manufacturing by incurring raw material to vaccination at the distribution center. The vaccine is lifesaving drugs at present so model does not consider shortages. The total cost which is sum of holding cost, purchase cost, inspection cost, ordering cost and carbon emissions cost is minimized.

\section{Notations}

In this section notations are exhibited which are used to construct the proposed model.

\begin{tabular}{|c|c|}
\hline \multicolumn{2}{|c|}{ Cost parameters } \\
\hline A & Set-up cost ( $\$$ /order $)$ \\
\hline$H$ & Holding cost (\$ /vaccine /unit of time) \\
\hline$C$ & Manufacturing cost (\$ /vaccine) \\
\hline$C_{p}$ & Purchase cost (\$ /vaccine) \\
\hline$C_{i}$ & Inspection cost (\$ /vaccine) \\
\hline$C_{T}$ & Carbon tax $(\$)$ \\
\hline$A_{c e}$ & $\begin{array}{l}\text { Amount of carbon emissions during manufacturing, } \\
\text { set-up and transportation (in } \mathrm{kg} \mathrm{CO}_{2} \text { ) }\end{array}$ \\
\hline$h_{c e}$ & $\begin{array}{l}\text { Amount of carbon emissions caused by holding } \\
\text { vaccines in the inventory system (in } \mathrm{kg} \mathrm{CO}_{2} \text { ) }\end{array}$ \\
\hline$C_{r c e}$ & $\begin{array}{l}\text { Amount of carbon emissions produced during } \\
\text { preparation time (in } \mathrm{kg} \mathrm{CO}_{2} \text { ) }\end{array}$ \\
\hline$C_{p c e}$ & $\begin{array}{l}\text { Amount of carbon emissions incurred during the } \\
\text { purchase operation (in } \mathrm{kg} \mathrm{CO}_{2} \text { ) }\end{array}$ \\
\hline$C_{i c e}$ & $\begin{array}{l}\text { Amount of carbon emissions during inspection } \\
\text { process (in } \mathrm{kg} \mathrm{CO}_{2} \text { ) }\end{array}$ \\
\hline \multicolumn{2}{|c|}{ Demand and spoilage parameters } \\
\hline$r$ & Inspection rate \\
\hline$\theta$ & $\begin{array}{l}\text { Rate of health warriers who did not turn up for } \\
\text { vaccination after registration }\end{array}$ \\
\hline$R$ & Scale demand in units \\
\hline \multicolumn{2}{|c|}{ Functions } \\
\hline$X$ & Percentage of spoiled vaccine due to miss-handling \\
\hline
\end{tabular}




\begin{tabular}{|c|c|}
\hline \multicolumn{2}{|c|}{ Cost parameters } \\
\hline$E[x]$ & Expected value of percentage of spoiled vaccine \\
\hline $1-E[x]$ & Expected value of percentage of quality vaccine \\
\hline$f(x)$ & $\begin{array}{l}\text { Probability density function of percentage of spoiled } \\
\text { vaccines }\end{array}$ \\
\hline \multicolumn{2}{|l|}{ Constants } \\
\hline$\alpha$ & Constant $>0$ \\
\hline$\beta$ & Constant $>0$ \\
\hline$\lambda$ & Linear growth rate for vaccine registration /unit $>0$ \\
\hline$v_{0}$ & Rate of initial registration to get vaccine $0 \leq v_{0} \leq 1$ \\
\hline$v_{1}$ & Rate of vaccination at respective time \\
\hline \multicolumn{2}{|c|}{ Time periods } \\
\hline$t_{1}$ & Manufacturing period in weeks \\
\hline$t_{2}$ & Inspection time for $Q$-units in weeks \\
\hline$t_{3}$ & Utilization time of vaccine after inspection in weeks \\
\hline$T$ & Cycle time $\left(t_{2}+t_{3}\right)$ in weeks \\
\hline \multicolumn{2}{|c|}{ Decision variables } \\
\hline$Q$ & Order quantity of vaccines (units) \\
\hline \multicolumn{2}{|c|}{ Objective function } \\
\hline$T C(Q)$ & Total cost per unit time ( $\$$ /unit time) \\
\hline \multicolumn{2}{|l|}{ Problem } \\
\hline \multicolumn{2}{|l|}{$\begin{array}{l}\text { Minimize } \\
T C(Q)\end{array}$} \\
\hline $\begin{array}{l}\text { Subject to } \\
\qquad Q>0\end{array}$ & \\
\hline
\end{tabular}

\section{Assumptions}

The proposed inventory model of vaccine is based on the assumption listed below:

(1) Only one type of vaccine is considered.

(2) Registration to take vaccines increases linearly at an approximately constant rate. (https://www.mohfw. gov.in/)

(3) The raw material cost of vaccine depends on demand of vaccine or the quantity of registration by the health warriers.

(4) Inspection is carried out to identify the fault free vaccine.

(5) The vaccine loses its utility due to maintenance at the rate $\theta(0 \leq \theta<1)$.

(6) Shortages are not allowed because health warriers are directly coming in contact with COVID-19 infectious patients.

\section{Problem description}

The objective of the proposed problem of vaccine inventory is to minimize the total cost of an inventory system per unit time which is sum of purchase cost (PC), ordering cost (OC), Manufacturing cost (RMC), holding cost (HC), inspection cost (IC) and carbon emissions cost (CEC).

\section{Model development}

The Indian COVID-19 vaccine needs to be stored at $2-8^{\circ} \mathrm{C}$. The power cut or voltage fluctuation in the inventory system results in spoilage of vaccine. Let the fraction of spoilage of vaccine be $x$, which is a random variable with $f(x)$ as the probability density function and expected value $E[x]$. Therefore, the expected total cost is given by

$E[T C]=P C+O C+R M C+E[H C]+I C+C E C$

The registration for vaccine follows logistic curve with function $v(t)=\frac{\alpha}{1+\beta e^{-\lambda t}}$, where $\alpha, \beta$ are positive constants and $\lambda>0$ represents linear growth rate of registration.

During manufacturing period $t_{1}$, registration is given by $v\left(t_{1}\right)=\frac{\alpha}{1+\beta e^{-\lambda t}}=v_{1}$ (say).

So, the manufacturing time $t_{1}$ is

$t_{1}=-\frac{1}{\lambda} \ln \left[\frac{1}{\beta}\left(\frac{\alpha}{v_{1}}-1\right)\right]$

These vaccines are thoroughly inspected at rate $r$. The inspection time $t_{2}$ is

$t_{2}=\frac{Q v_{1}}{r}$

Under assumption that $x$ fraction of spoilage vaccine is to be dumped, the utilization time of vaccine after inspection and dumping $t_{3}$ is given by

$t_{3}=\frac{Q v_{1}-R t_{2}-E[x] Q v_{1}}{R}$

Hence, the cycle time $T$ is the sum of $t_{2}$ and $t_{3}$. i.e.

$T=t_{2}+t_{3}=\frac{Q v_{1}}{R}(1-E[x])$

Next, we compute different cost components related to proposed problem.

Since, initial registration for vaccination is $v_{0}$, the purchase cost is given by

Purchase cost $P C=C_{p} Q v_{0}$

A fixed set-up cost occurs at the beginning of each cycle, thus the ordering cost per cycle is

Ordering cost $O C=A$ 
The vaccines are produced during 0 to $t_{1}$ with a manufacturing $\operatorname{cost} C$ per vaccine and so the manufacturing cost is given by:

Manufacturing cost $R M C$

$$
=C Q\left[\alpha t_{1}+\frac{\alpha}{\lambda}\left(\ln (1+\beta) e^{-\lambda t_{1}}-\ln (1+\beta)\right)\right]
$$

The organization invest in a holding cost for preserving vaccines. So expected holding cost is

$$
\begin{aligned}
E[H C]= & h\left[\frac{Q^{2} v_{1}\left[E(1-x)^{2}\right]}{2 R}-\frac{Q v_{1}(1-E[x])}{R}+\frac{1}{2 R}\right. \\
& \left.+\frac{Q^{2} v_{1}^{2} E[x]}{r}-\frac{Q v_{1} E[x]}{r}+\frac{Q v_{1}}{r}\right]
\end{aligned}
$$

During $t_{1}$ to $t_{2}$ an inspection process is carried out to inspect and separate the defective vaccine from the perfect ones. The organization acquires in an inspection with rate $C_{i}$ per vaccine and the inspection cost is

Inspection cost $I C=C_{i} Q v_{1}$

Next we compute carbon emissions. The carbon emissions occur from the beginning of manufacturing till it reaches to the customer. The carbon emission is caused due to procedures such as manufacturing, purchasing, set-up, holding inventories and inspection. Carbon emission caused by the purchasing activity is given below:

$C E P=C_{p c e} Q v_{0}$

Carbon emissions due to setup activity $C E S=A_{c e}$

Carbon emission produced during the manufacturing process is

$C R M=C_{r c e} Q\left[\alpha t_{1}+\frac{\alpha}{\lambda}\left(\ln (1+\beta) e^{-\lambda t_{1}}-\ln (1+\beta)\right)\right]$

Carbon emission observed in holding inventory operations is $\mathrm{CHC}$.

$$
\begin{aligned}
C H C= & h_{c e}\left[\frac{Q^{2} v_{1}\left[E(1-x)^{2}\right]}{2 R}-\frac{Q v_{1}(1-E[x])}{R}+\frac{1}{2 R}\right. \\
& \left.+\frac{Q^{2} v_{1}^{2} E[x]}{r}-\frac{Q v_{1} E[x]}{r}+\frac{Q v_{1}}{r}\right]
\end{aligned}
$$

Carbon emission spawned in the process of inspection.

$C E I=C_{i c e} Q v_{1}$

Carbon tax is one of the important policy which is imposed by government regulation on amount of carbon emissions.

$C E C=C_{T}[C E P+C E S+C R M+C H C+C E I]$
From Eqs. (6) to (10) and (16), the expected total cost of an inventory system is:

$E[T C]=P C+O C+R M C+E[H C]+I C+C E C$ and expected cycle time $E[T]=\frac{Q v_{1}}{R}(1-E[x])$ so expected total cost $T C$ per time unit is

$T C=\frac{E[T C]}{E[T]}=\frac{P C+O C+R M C+E[H C]+I C+C E C}{E[T]}$

is a function of order quantity $Q$, for optimal value of $Q$, we need to set $\frac{d T C}{d Q}=0$, where

$$
\begin{aligned}
& \frac{d T C}{d Q}=\frac{1}{3\left(r Q^{2} v_{1}(-2+a+b)\right)} \\
& \left(\begin{array}{r}
-C_{T} C_{p c e} Q^{2} v_{1}^{2} a^{2} r \theta-C_{T} C_{p c e} Q^{2} v_{1}^{2} a b r \theta-C_{T} C_{p c e} Q^{2} v_{1}^{2} b^{2} r \theta \\
-3 C_{T} C_{p c e} Q^{2} R v_{1}^{2} a \theta-3 C_{T} C_{p c e} Q^{2} R v_{1}^{2} b \theta+3 C_{T} C_{p c e} Q^{2} v_{1}^{2} a r \theta \\
+3 C_{T} C_{p c e} Q^{2} v_{1}^{2} b r \theta-C_{T} Q^{2} v_{1}^{2} a^{2} h_{c e} r-C_{T} Q^{2} v_{1}^{2} a b h_{c e} r \\
-C_{T} Q^{2} v_{1}^{2} b^{2} h_{c e} r-C_{p} Q^{2} v_{1}^{2} a^{2} r \theta-C_{p} Q^{2} v_{1}^{2} a b r \theta-C_{p} Q^{2} v_{1}^{2} b^{2} r \theta \\
-3 C_{T} C_{p c e} Q^{2} v_{1}^{2} r \theta-3 C_{T} Q^{2} R v_{1}^{2} a h_{c e}-3 C_{T} Q^{2} R v_{1}^{2} b h_{c e} \\
+3 C_{T} Q^{2} v_{1}^{2} a h_{c e} r+3 C_{T} Q^{2} v_{1}^{2} b h_{c e} r-3 C_{p} Q^{2} R v_{1}^{2} a \theta \\
-3 C_{p} Q^{2} R v_{1}^{2} b \theta+3 C_{p} Q^{2} v_{1}^{2} a r \theta+3 C_{p} Q^{2} v_{1}^{2} b r \theta-Q^{2} v_{1}^{2} a^{2} h r \\
-Q^{2} v_{1}^{2} a b h r-Q^{2} v_{1}^{2} b^{2} h r-3 C_{T} Q^{2} v_{1}^{2} h_{c e} r-3 C_{p} Q^{2} v_{1}^{2} r \theta \\
-3 Q^{2} R v_{1}^{2} a h-3 Q^{2} R v_{1}^{2} b h+3 Q^{2} v_{1}^{2} a h r+3 Q^{2} v_{1}^{2} b h r-3 Q^{2} v_{1}^{2} h r \\
+6 A_{c e} C_{T} R r+6 A R r
\end{array}\right)
\end{aligned}
$$

\section{Numerical validation}

In this section, numerical example is demonstrated to show the applicability of the proposed model and explain the solution steps. The objective is to minimize the total cost which can be obtained by following steps:

Step 1: Differentiate total cost function given in Eq. (17) with respect to order quantity $Q$.

Step 2: Assign the values to all inventory parameters other than order quantity.

Step 3: Taking cost function is zero, in order to get solutions.

Step 4: Find the values of all cost functions and decision variable.

The following hypothetical data are considered to validate the model. 
$\alpha=2, C_{p}=\$ 1.2$ per vaccine, $\lambda=0.60$,

$A=\$ 1000$ per order, $C=\$ 1$ per vaccine,

$h=\$ 0.40$ per vaccine,

$C_{i}=\$ 4$ per vaccine, $C_{T}=0.40, C_{p c e}=0.2$,

$A_{c e}=50, C_{r c e}=0.06, h_{c e}=0.005, C_{i c e}=0.12$,

$R=\$ 600$ per order, $r=0.9, \theta=0.1, v_{0}=0.9$,

$v_{1}=0.8$

The percentage of spoilage vaccine follows a uniform distribution $(x \sim U[\gamma, \delta])$ with the probability density function $f(x)$ which is given below.

$x \sim f(x)=\left\{\begin{array}{cc}\frac{1}{\delta-\gamma} & \gamma \leq x \leq \delta \\ 0 & \text { otherwise }\end{array}\right.$

Considering $(x \sim U[0,0.04])$

$x \sim f(x)=\left\{\begin{array}{cc}25 & 0 \leq x \leq 0.04 \\ 0 & \text { otherwise }\end{array}\right.$

The various optimal costs are:

As shown in Fig. 1, the various optimal costs are: raw materil cost $\$ 1280$, inspection cost $\$ 2449$, purchase cost $\$ 826.5$, ordering cost $\$ 2116$, inventory holding cost $\$ 2120$ and carbon emission cost $\$ 198.1$ resulting total cost per unit time is $\$ 8980$ to procure 361 vaccine units. Each vaccine unit consists of 100 vaccines. The obtained total cost is minimum because $\frac{d^{2} T C}{d T^{2}}=0.04>0$.

During the process of vaccination starting from raw material inventory in the pharmacutical company, carbon emissions are observed. As per Fig. 2 carbon emission in stocking raw material \$30.5, during inspection $\$ 29.79$, during purchase action $\$ 55.10$, during set-up and transporatation phase $\$ 42.33$ and holding it at point of delivery $\$ 40.79$. Then carbon tax lavied is $\$ 198$. 1 . From Fig. 2, it is observed that maximum carbon emission of $28 \%$ occurs during purchase process followed by $21 \%$ during transporation at point of delivery and stocking it at respective places. This is obvious because of fuel consumption and cold storage which emits gases.

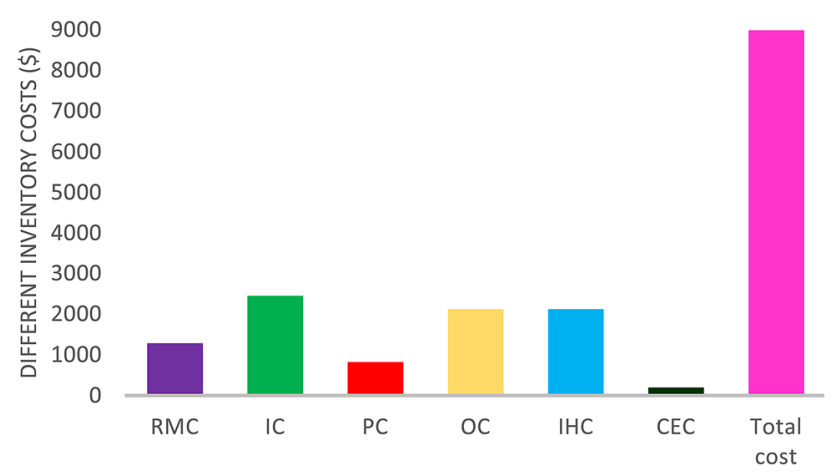

Fig. $1 \mathrm{xxx}$

\section{Sensitivity analysis}

In this section, the sensitivity analysis is carried out with different inventory parameters. When the value of one inventory parameter is changed by $-20 \%,-10 \%, 10 \%$ and $20 \%$ at a time and keeping others parameters unchanged is shown in Table 2.

As depicted in Table 2 , changes in purchase cost $C_{p}$, setup cost $A$, manufacturing $\operatorname{cost} C$, holding $\operatorname{cost} h$, Inspection cost $C_{i}$ and Scale demand $R$ have a major impact on total cost. While constant $\alpha$, growth rate $\lambda$, inspection rate $r$ and $v_{1}$ have a revisable effect on total cost. Carbon tax $C_{T}$, carbon emissions during the purchase cost $C_{p c e}$, amount of carbon emission during set-up cost $A_{c e}$, amount of carbon emission during preparation time $C_{r c e}$, amount of carbon emissions during holding the inventory $h_{c e}$, carbon emission during the inspection process $C_{i c e}$, rate of health warriers who didn't take vaccination $\theta$ and initial registration of vaccination $v_{0}$ have marginal effect on total cost. The order quantity $Q$ gets positively affected by set-up cost and inspection rate while it decreases with increases in parameters $C_{p}, h, \theta$ and $v_{1}$. The Rest of the inventory parameters have a negligible effect on order quantity. Carbon emission caused by purchasing cost increases with increases in carbon tax, $C_{p c e}, R$ and $v_{0}$, while decreases with $v_{1}$. Carbon emission due to set-up is positively affected by $C_{p}, h, C_{T}, A_{c e}, R, \theta$ and decreases with $A$ and $r$. $C_{T}, C_{r c e}$ and $R$ are the most sensitive parameters of carbon emission during manufacturing CRM. $\alpha$ and $\lambda$ have a reversible impact on $C R M$. Carbon emission during holding the items $C H C$ is increases when $A, C_{T}, C_{p c e}, h_{c e}, R$ and $\theta$ increases. Conversely $C H C$ decreases with increases in $C_{p}, h$ and $r$. The carbon tax and carbon emission during inspection has the most significant impact on carbon emissions generated during the inspection $C E I$. CEC is positively affected by $C_{T}, C_{p c e}, A_{c e}, C_{r c e}, C_{i c e}, R, \theta$ and $v_{0}$ while it decreases with $\lambda, r$ and $v_{1} . C_{p}, R$ and $v_{0}$ give rise to purchase cost whereas purchase cost reduces due to $v_{1}$. Moreover, $C_{p}, A, h, R$ and $\theta$ have a positive impact on

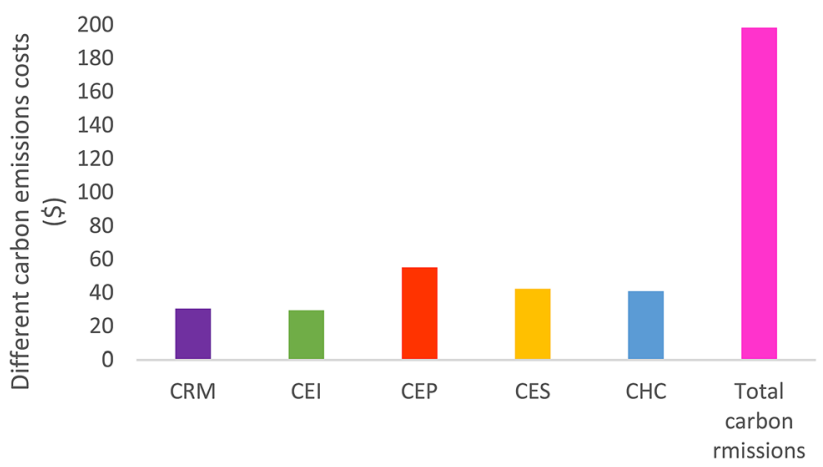

Fig. 2 yуy 
Table 2 Sensitivity analysis

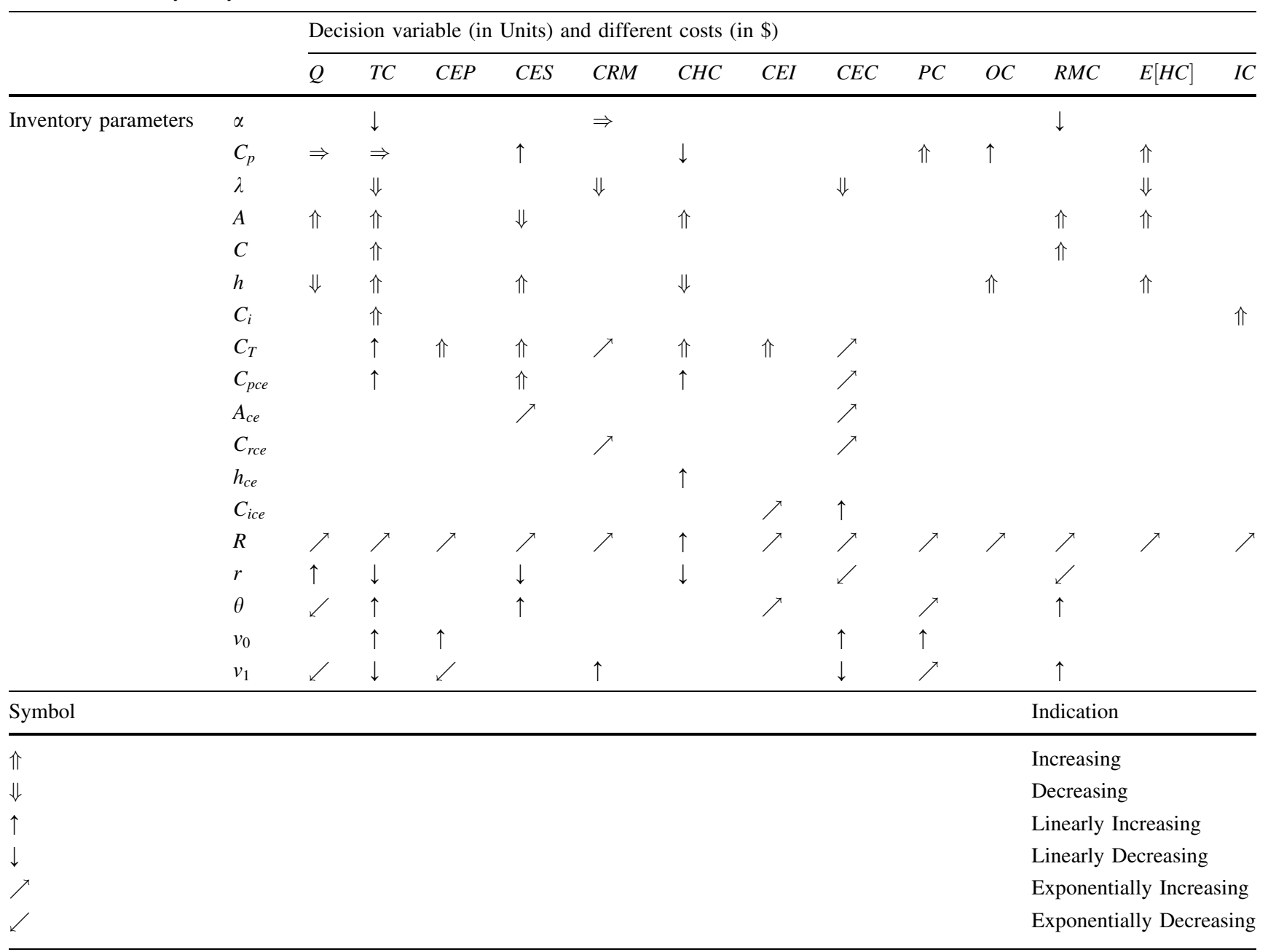

ordering cost. Manufacturing cost gets increased with $C, R$ and $v_{1}$. Parameters $\alpha$ and $\lambda$ have a negative impact on $R M C$. Holding cost increases when $C_{p}, A, h, R$ and $\theta$ increases whereas it decreases with inspection rate. Inspection cost $C_{i}$ and scale demand are the most sensitive parameters to inspection cost $I C$.

\section{Discussion of findings}

In Table 3, we carry out the analysis of critical parameters for the proposed problem of inventory of vaccines and carbon emissions due to process involved.

\section{Manegerial implication}

From the sensitivity analysis Table 2, the following manegerial insights are made:
Scale demand has major effect on order quantity, total cost, and carbon emissions during activity like purchase, holding set-up, manufacturing and inspection. Moreover, a bigger order size gives rise to carbon emissions but also increase the sell, so it is advisable to place larger order for a short period of time. Set-up cost and purchase cost increases manufacturing cost as well as total cost. Holding cost decreases the order quantity. A higher holding cost indicates better-quality storage condition and it increase the total cost. Hence, it is recommended that order in small lots so inventory can be handled, which is also reduce carbon emissions. As increase in carbon tax contributes to the total cost components which is unfavorably. Manufacturing cost is directly affected by demand. So proper technology should be employed. Rate of health warriers who did not turn up for vaccination after registration is directly increase total cost as well carbon emissions and also increase the risk of COVID-19 infection. Initial registration directly affect the manufacturing, transshipping and holding. 
Table 3 Sensitivity analysis of critical parameters

Impact of initial registration on $C E P$

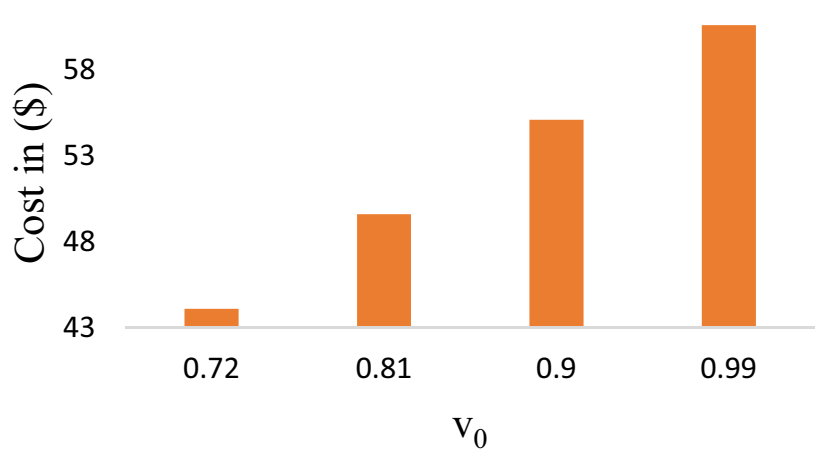

Impact of $\lambda$ on $C R M$

39

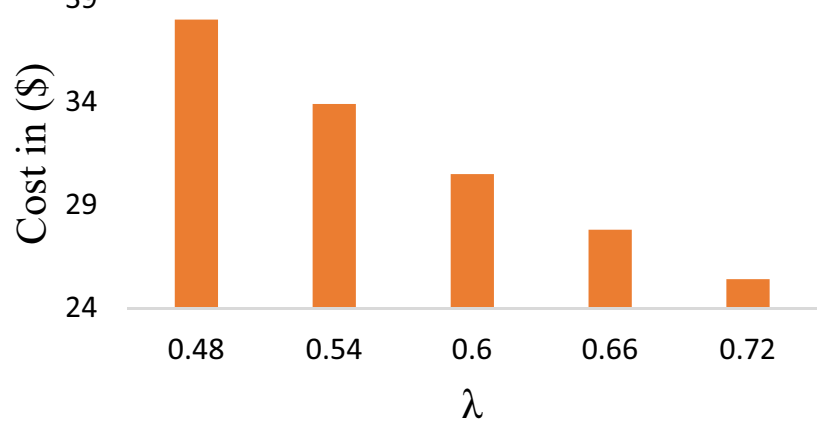

Impact of $C_{r c e}$ on $C R M$

40

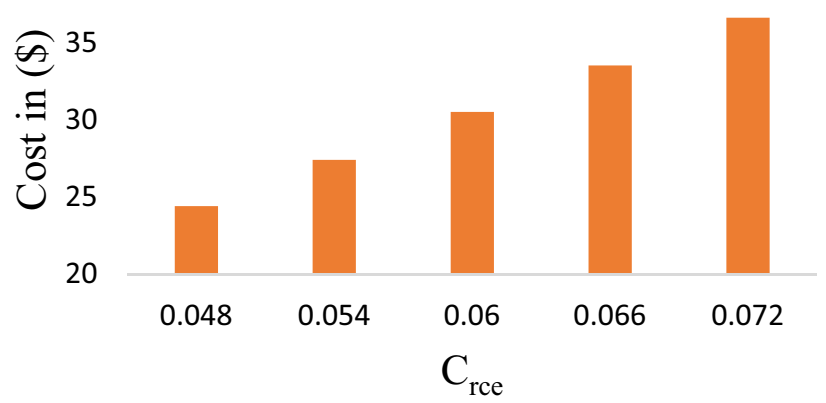

In the adjacent figure, the impact of initial registrations on carbon emissions due to purchase action is shown. The purchase order directly reflects to the manufacturing, transporation and stocking. The carbon emission increases by $27.27 \%$

In the adjacent figure, the linear rate of registration is studied on carbon emissions due to raw material stocking. Here, the carbon emissions reduces by $33.16 \%$ when registration rate increases from 48 to $72 \%$. This is because raw material is gone to production of vaccine phase

In this figure, $C_{r c e}$ is varied from 0.048 to 0.072 which increases carbon emissions during manufacturing by $50 \%$. So the proper technology investment should be deployed to reduce this 
Table 3 continued

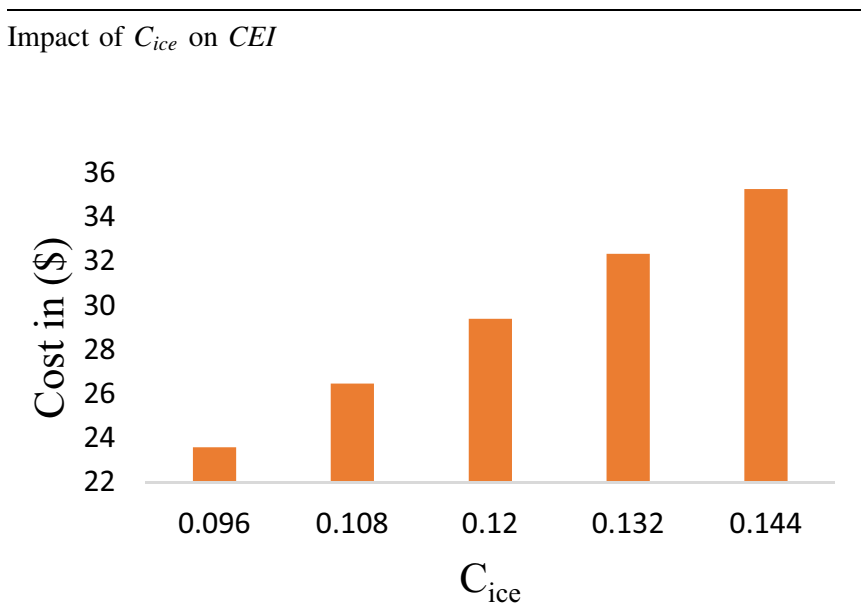

In this adjacent figure when carbon emissions occurred during inspetion is varied from $-20 \%$ to $20 \%$, to cost of carbon emission increases by $49.72 \%$

Here, when purchase cost is varried from $\$ 0.96$ to $\$ 1.44$, carbon emissions due to set-up increases by $4.66 \%$ and due to holding cost decreases by $7.35 \%$

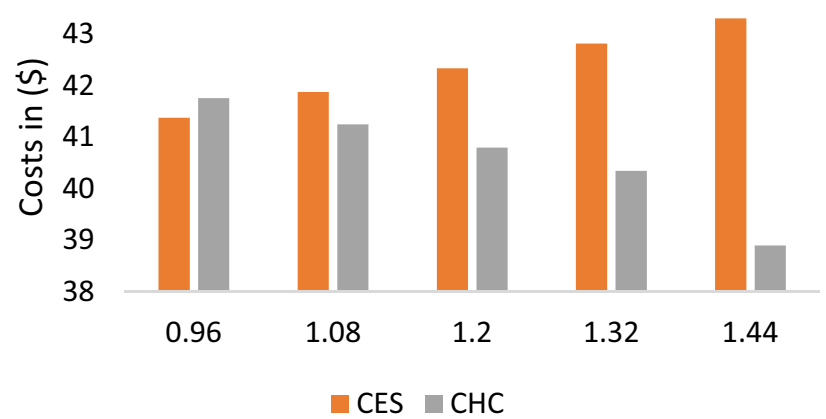

Impact of $C_{p c e}$ on $C E P$ and $C H C$

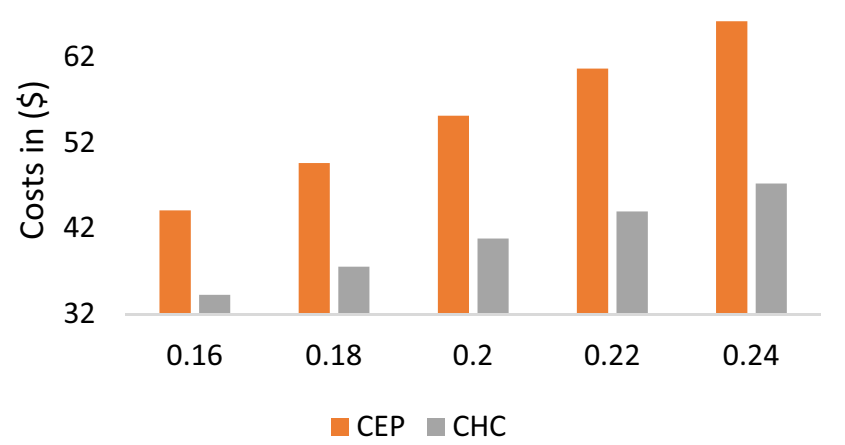

Carbon emission cost due to purchasing; $C_{p c e}$ results $50 \%$ increase in carbon emission due to set-up and $37.84 \%$ in carbon emission during stocking 
Table 3 continued

Impact of set-up cost on $C E S$ and $C H C$

Increase in set-up cost, decrease carbon emissions due to set-up by $18 \%$ and increase carbon emission due to holding cost by $21.95 \%$

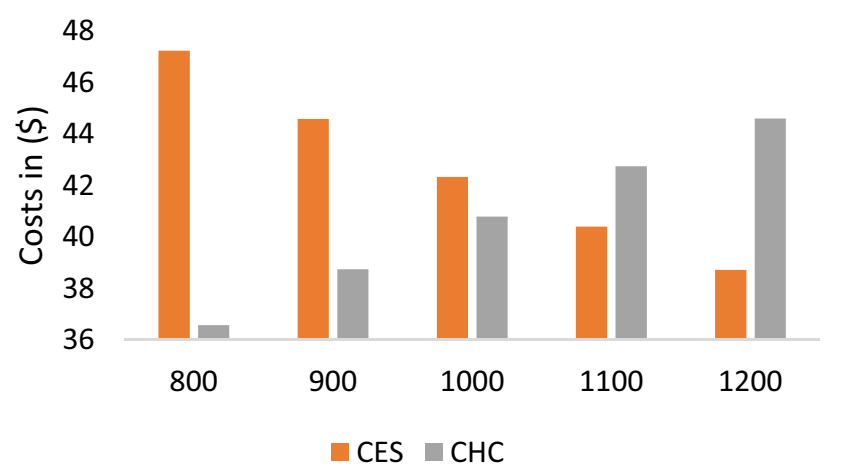

Impact of $A_{c e}$ on $C E S$

52

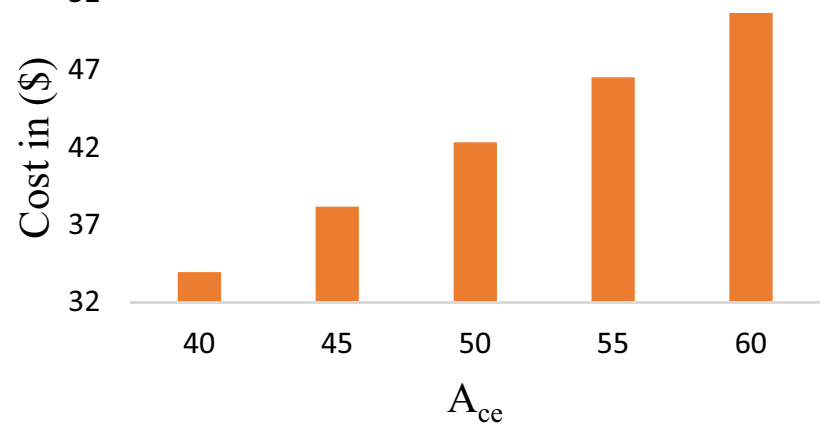

When $A_{c e}$ increases from $\$ 40$ to $\$ 60$, carbon emission cost due to setup increases by $49.42 \%$. This can be controlled by designing special vehicles for transporting vaccines to the point of delivery
- 20 to $20 \%$ variation holding cost results into $16.48 \%$ increase and $14.16 \%$ decrease in carbon emissions due to set-up and stocking operations respectively

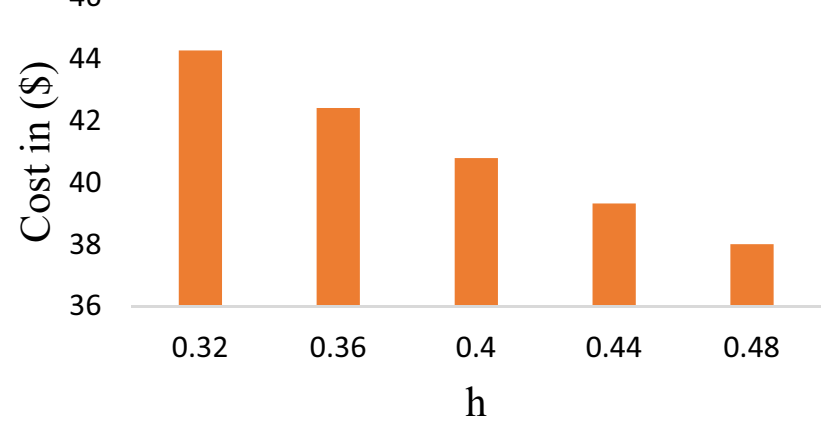


Table 3 continued

\section{Impact of $v_{1}$ on $C E S$ and $C H C$}

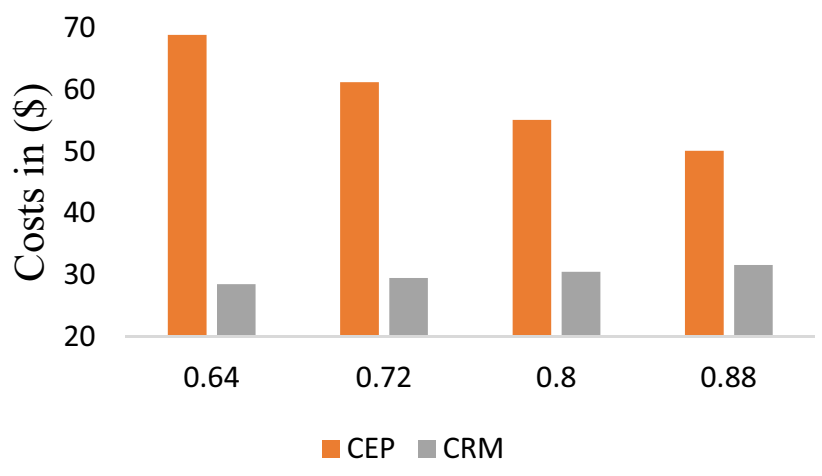

Impact of $\theta$ on $C E S$ and $C H C$

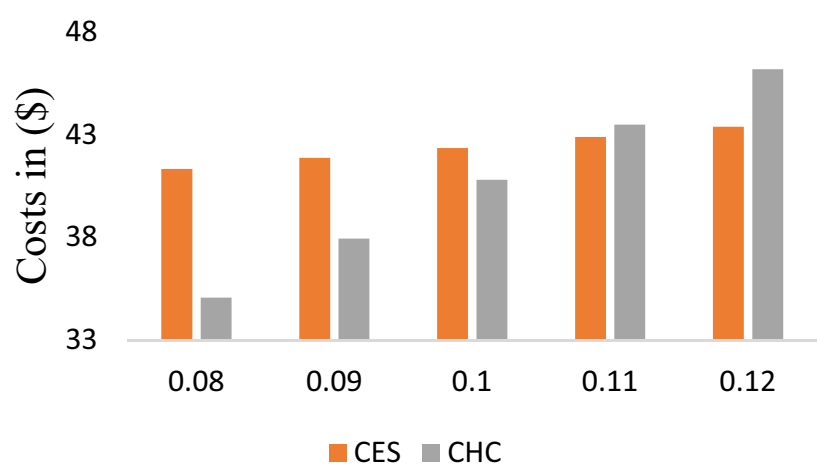

Change in $v_{1}$ decreases carbon emission due to procurement by $27.28 \%$ and increases carbon emission due to raw material stocking $10.88 \%$
The effect of spoilage of vaccines during storage or transporation on carbon emissions during set-up and stocking operations is exhibited here. It is $4.96 \%$ and $3.17 \%$ respectively. This is not affordable as it wastes raw material for vaccines and end-user will also not able to get vaccination which puts a good fraction of population at the risk of infection of COVID-19

\section{Conclusion}

Attributed to the invention of COVID-19 vaccines, people around the world were offered a hope that the pandemic may come to an end soon. But the gradual relief from this said pandemic will bring back to the biggest challenge currently faced by humans which is carbon emissions. This articles shows detailed analysis of carbon emissions during manufacturing, transportation and stocking. In order to reduce carbon emissions, it can be suggested vehicles which are used in transporting are well designed, the proper technology for manufacturing can be deployed and individuals should encourage for not to skip schedule second dose of vaccine. The spoilage of vaccine during storage is not affordable as it waste raw material and needed people are not get vaccine. The model is examined analytically and graphically by minimizing the total cost. A sensitivity analysis is performed to scrutinize how each inventory parameters affects the total cost and carbon emissions cost.

Acknowledgements The authors thank DST-FIST file \# MSI-097 for the technical support to the department. The authors thanks to reviewers.

Funding Ekta Patel would like to extend sincere thanks to the Education Department, Gujarat State for providing scholarship under ScHeme OF Developing High quality research (Student Ref No : 201901380184). Kavita Rabari funded by a Junior Research Fellowship from the Council of Scientific \& Industrial Research (File No.-09/070(0067)/2019-EMR-I).

\section{Declarations}

Conflict of interest The authors does not have conflict of interest. 
Human and animals participants Not applicable.

Informed consent Not applicable.

\section{References}

Absi N, Dauzère-Pérès S, Kedad-Sidhoum S, Penz B, Rapine C (2013) Lot sizing with carbon emission constraints. Eur J Oper Res 227(1):55-61

Afzal AR, Alfares HK (2021) An Inventory Model for Growing Items with Quality Inspections and Permissible Shortages. International Conference on Industrial Engineering and Operations ManagementDetroit, Michigan, USA, pp. 1153-1160

Alfares HK, Afzal AR (2021) An economic order quantity model for growing items with imperfect quality and shortages. Arab J Sci Eng 46(2):1863-1875

Datta TK (2017) Effect of green technology investment on a production-inventory system with carbon tax. Adv Op Res 2017:1-12

Dye CY, Yang CT (2015) Sustainable trade credit and replenishment decisions with credit-linked demand under carbon emission constraints. Eur J Oper Res 244(1):187-200

Hidayat YA, Riaventin VN, Jayadi O (2020) Economic order quantity model for growing items with incremental quantity discounts, capacitated storage facility, and limited budget. Jurnal Teknik Industri 22(1):1-10

Hua G, Cheng TCE, Wang S (2011a) Managing carbon footprints in inventory management. Int J Prod Econ 132(2):178-185

Hua G, Qiao H, Li J (2011b) Optimal order lot sizing and pricing with carbon trade. SSRN Electron J. https://doi.org/10.2139/ssrn. 1796507

Khalilpourazari S, Pasandideh SHR (2019) Modeling and optimization of multi-item multi-constrained EOQ model for growing items. Knowl-Based Syst 164:150-162
Lou GX, Xia HY, Zhang JQ, Fan TJ (2015) Investment strategy of emission-reduction technology in a supply chain. Sustainability 7(8):10684-10708

Malekitabar M, Yaghoubi S, Gholamian MR (2019) A novel mathematical inventory model for growing-mortal items (case study: rainbow trout). Appl Math Model 71:96-117

Mishra U, Wu JZ, Sarkar B (2020) A sustainable productioninventory model for a controllable carbon emissions rate under shortages. J Clean Prod 256:120268

Mishra U, Wu JZ, Sarkar B (2021) Optimum sustainable inventory management with backorder and deterioration under controllable carbon emissions. J Clean Prod 279:123699

Nobil AH, Sedigh AHA, Cárdenas-Barrón LE (2019) A generalized economic order quantity inventory model with shortage: case study of a poultry farmer. Arab J Sci Eng 44(3):2653-2663

Rezaei J (2014) Economic order quantity for growing items. Int J Prod Econ 155:109-113

Sebatjane M, Adetunji O (2019a) Economic order quantity model for growing items with incremental quantity discounts. J Ind Eng Int 15(4):545-556

Sebatjane M, Adetunji O (2019b) Economic order quantity model for growing items with imperfect quality. Op Res Perspect 6:100088

Sebatjane M, Adetunji O (2019c) Three-echelon supply chain inventory model for growing items. J Model Manag 15(2):567-587. https://doi.org/10.1108/JM2-05-2019-0110

Toptal A, Özlü H, Konur D (2014) Joint decisions on inventory replenishment and emission reduction investment under different emission regulations. Int J Prod Res 52(1):243-269

Zhang Y, Li LY, Tian XQ, Feng C (2016) Inventory management research for growing items with carbon-constrained. In 2016 35th Chinese Control Conference (CCC) (pp. 9588-9593). IEEE.

Publisher's Note Springer Nature remains neutral with regard to jurisdictional claims in published maps and institutional affiliations. 